\title{
Rainfall infiltration simulation on embankment containing soluble material
}

\author{
Katsuyuki Kawai ${ }^{1, *}$, Kaito Arinishi ${ }^{2}$, Satsuki Kataoka ${ }^{3}$, and Koji Nakashima ${ }^{1}$ \\ ${ }^{1}$ Kindai University, Department of Civil and Environmental Engineering, 3-4-1 Kowakae Higashi-Osaka Osaka, Japan \\ ${ }^{2}$ Kindai University, Graduate School of Science and Engineering, 3-4-1 Kowakae Higashi-Osaka Osaka, Japan \\ ${ }^{3}$ Kobe University, Department of Civil Engineering, 1-1 Rokkoudai-cho Nada Kobe Hyogo, Japan
}

\begin{abstract}
Recently, mixtures of low-quality soil together with solidification materials, such as cement or steel slag, have been used for earthmoving construction. Solidification materials can improve consistency, shear strength, stiffness, and other parameters of low-quality soil by generating bonding forces between soil particles and changing grain size gradation. However, these solidification materials also contain chemical agents. In this study, simulations of rainfall infiltration into embankment constructed with the soilsolidification material mixture are conducted using the soil/water/air/soluble material coupled finite element analysis code, DACSAR-MP_ad. This analysis code can express not only deformation and seepage for an unsaturated earth structure but can also concurrently model the dispersing behaviour of soluble material. Herein, permeability and rainfall intensity conditions are provided and their effects investigated. Consequently, this study succeeds in expressing different distributions of soluble materials within embankment under different rainfall conditions.
\end{abstract}

\section{Introduction}

Construction waste soil may be used for constructing embankment. Embankment consisting of such lowquality soil materials exhibits low stability under rainfall and in the event of earthquakes. When low-quality material must be used for construction, solidification materials, such as cement and steel slag, are mixed with soil to improve its mechanical properties. The solidification material reacts with water contained in the soil and generates bonding among soil particles. When this happens, we can expect an increase in stiffness and a change in grain size gradation. However, the solidification materials contain chemical agents. Since most earth structures are exposed to natural weather conditions, it is of concern that chemical materials may leach from the earth structure, due to inflow and outflow, and disperse into the surrounding environment. A way to construct and to maintain embankment containing soluble soil materials without leaching is needed for the effective use of solidification material.

The embankment model shown in Fig.1 was conducted using a mixture of soil with steel slag, and tests were conducted to monitor rainfall infiltration behaviour. Moreover, the $\mathrm{pH}$ of water leached from the embankment was measured during the next day of rainfall. Figure 2 shows the measurement results. In the figure, $\mathrm{pH}$ obtained from the tank leaching test from the mixture of soil with steel slag is expressed as a dashed line of $\mathrm{pH}=12.4$. Though a gradually decreasing trend with time after construction can be seen, rainfall

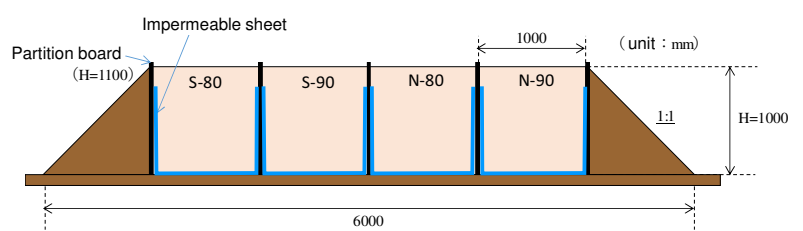

(a) Front view

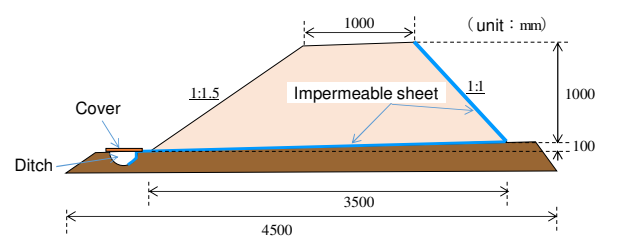

(b) Cross-section view

Fig. 1. Embankment model

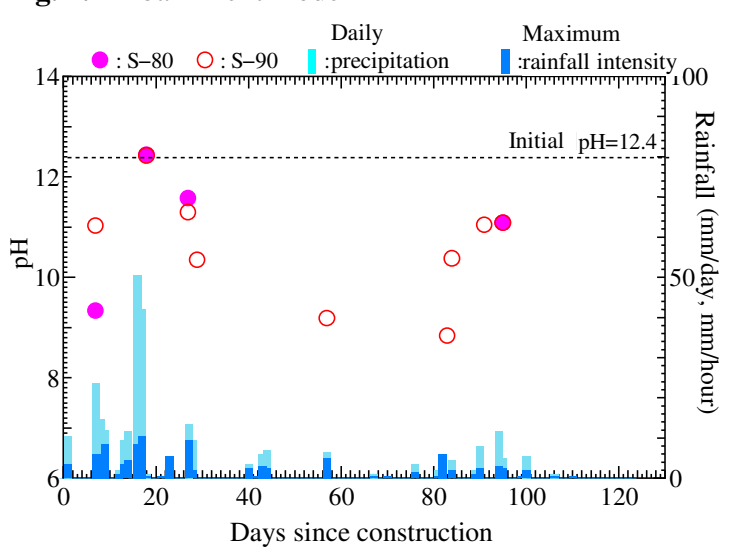

Fig. 2. Measured $\mathrm{pH}$ of water leached from the embankment

\footnotetext{
Corresponding author: kkawai@ civileng.kindai.ac.jp
} 


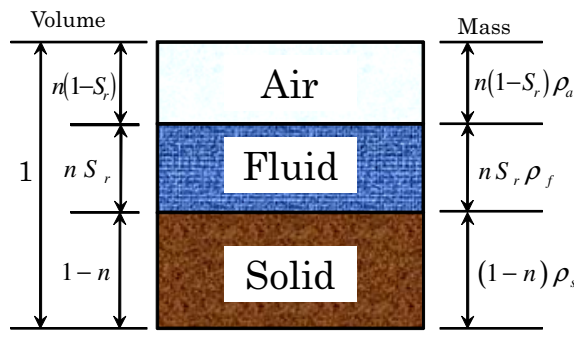

Fig. 3. Model of soil material

continues to generate alkaline material leachate, with a high $\mathrm{pH}$ measured after strong rainfall. Consequently, this shows that rainfall infiltration behaviour depends strongly on rainfall intensity and total amount, which subsequently influences alkaline leaching. In this study, rainfall infiltration into soil embankment constructed with soluble materials was simulated, and the effects of rainfall on the transfer of soluble material were investigated.

\section{Numerical model used for simulation}

To express the effects of embankment rainfall infiltration on soluble material leaching, the soil/water/air/soluble material coupled finite element analysis code DACSARMP_ad was used. The relative solute concentration, $c$, is expressed as a variable of normalized concentration to the saturated solubility of pore water, $\gamma$. Additionally, solid and fluid phases are assumed incompressible.

\subsection{Continuity equations and the mass transfer equation}

Soil materials were modelled as in Fig. 3 based on the multi-phase material theory. The principle of mass conservation of each phase can be formulated as follows. The suffix, $\alpha=s, f, a, c$, indicates each phase distinctively.

$$
\not{\rho}_{\alpha}^{\&}+\bar{\rho}_{\alpha} \operatorname{div} \mathbf{v}_{\alpha}=0\left(\bar{\rho}_{\alpha}=\phi_{\alpha} \rho_{\alpha}\right)
$$

Here, $\mathbf{v}$ is the actual velocity; $\varepsilon_{v}$ is the volumetric strain; $\rho$ and $\bar{\rho}$ are the actual and relative density, respectively; and $\phi$ is the volume fraction. The continuity equation between solid and air phases can be expressed by the following equation through the application of the gas state equation.

$$
\operatorname{div} \Theta_{a}=\left(1-S_{r}\right) \underset{v}{\&}+n S_{r}^{\&}-\frac{n\left(1-S_{r}\right)}{p_{a}+p_{0}} \&_{a}^{\&}
$$

Here, $\theta / c$ is the relative velocity; $p_{a}$ is air pressure; and $p_{0}$ is the gauge pressure. The mass transfer equation between solid and soluble material can be expressed by the following equation through the application of mass conservation.

$$
-S_{r} c \&+n+n S_{r}^{\&}+n S_{r} \&+\operatorname{div}\left(c \sigma_{f}\right)+n S_{r} \operatorname{div} \mathbf{J}=0
$$

Here, $\mathbf{J}$ is the concentration flux. The flux of water and material can be expressed by the following equations.

Darcy's law (Fluid) $\theta_{f}=-k_{f} k_{r f} \cdot \operatorname{grad} h$

Darcy's law (Air) $\forall_{a}=-k_{a} k_{r a} \cdot \operatorname{grad} h_{a}$

Fick's law

$$
\mathbf{J}=-\mathbf{D} \cdot \operatorname{grad} c
$$

$$
\begin{gathered}
k_{r f}=S_{e}^{1 / 2}\left[1-\left(1-S_{e}^{1 / m}\right)^{m}\right]^{2} \\
k_{r a}=\left(1-S_{e}\right)^{1 / 2}\left(1-S_{e}^{1 / m}\right)^{2 m} \\
S_{e}=\frac{S_{r}-S_{r c}}{1-S_{r c}}
\end{gathered}
$$

Here, $h$ is the total water head; $h_{a}$ is the water head of air pressure; $k_{f}$ is water permeability under fully saturated conditions; $k_{a}$ is the air permeability under completely dry conditions; $k_{r f}$ and $k_{r a}$ are the relative water and air permeability, respectively; and $\mathbf{D}$ is the tensor of the dispersion coefficient. The equations (8) and (9) are based on Mualem's model [1] and Lenhard and Parker's model [2], respectively. Furthermore, $m$ is Mualem's coefficient; $S_{e}$ is the effective degree of saturation; $S_{r}$ is degree of saturation; and $S_{r c}$ is the critical degree of saturation.

\subsection{Constitutive model for unsaturated soil}

The effective stress for unsaturated soil is expressed by the following equation.

$$
\boldsymbol{\sigma}^{\prime}=\boldsymbol{\sigma}^{n e t}+p_{s} \mathbf{1}
$$

Here, $\boldsymbol{\sigma}^{\text {net }}=\boldsymbol{\sigma}-p_{a} \mathbf{1} ; p_{s}=S_{e} s ;$ and $s=p_{a}-p_{w} . \boldsymbol{\sigma}^{\prime}$ is the effective stress tensor; $\boldsymbol{\sigma}^{\text {net }}$ is the net stress tensor; $\boldsymbol{\sigma}$ is total stress tensor; $p_{s}$ is suction stress; $\mathbf{1}$ is the second-order unit tensor; $s$ is suction; and $p_{w}$ is pore water pressure. The yield function for unsaturated soil, proposed by Ohno et al. (2007) [3], is expressed as follows.

$$
f\left(\boldsymbol{\sigma}^{\prime}, \zeta, \varepsilon_{v}^{p}\right)=M D \ln \frac{p^{\prime}}{\zeta p_{s a t}^{\prime}}+\frac{M D}{n_{E}}\left(\frac{q}{M p^{\prime}}\right)^{n_{E}}-\varepsilon_{v}^{p}=0
$$




$$
\begin{gathered}
\zeta=\exp \left[\left(1-S_{e}\right)^{n_{s}} \ln a\right], M D=\frac{\lambda-\kappa}{1+e_{0}} \\
p^{\prime}=\frac{1}{3} \boldsymbol{\sigma}^{\prime}: \mathbf{1}, q=\sqrt{\frac{3}{2} \mathbf{s}: \mathbf{s}, \mathbf{s}=\boldsymbol{\sigma}^{\prime}-p^{\prime} \mathbf{1}=\mathbf{A}: \boldsymbol{\sigma}^{\prime}, \mathbf{A}=\mathbf{I}-\frac{1}{3} \mathbf{1} \otimes \mathbf{1}}
\end{gathered}
$$

Here, $n_{E}$ is a shaping parameter; $\varepsilon_{v}^{p}$ is plastic volumetric strain; $M$ is the stress ratio $q / p^{\prime}$ at the critical state; $D$ is the dilatancy coefficient; $p_{\text {sat }}^{\prime}$ is the yield stress at saturation; $a$ and $n_{s}$ are the parameters expressing the yield stress increment due to desaturation; and $\lambda$ and $\kappa$ are compression and expansion indices, respectively. The following elasto-plastic constitutive equations can be obtained from Eq. (12).

$$
\begin{aligned}
& \boldsymbol{\sigma}^{\prime}=\mathbf{D}^{\mathrm{ep}}: \mathbf{d} \cdot \mathbf{C} \cdot S_{e}^{\&} \\
& \&=\frac{1}{2} \operatorname{div}\left(\mathbf{u}+\mathbf{u}^{T}\right)
\end{aligned}
$$

Here, $\mathbf{D}^{\mathbf{e p}}$ is the elasto-plastic stiffness tensor; $\boldsymbol{\varepsilon}$ is strain tensor; $\mathbf{C}$ is the tensor that expresses the change in stiffness due to desaturation; and $\mathbf{u}$ is the displacement vector. The soil water retention characteristic curve, which expresses the relationship

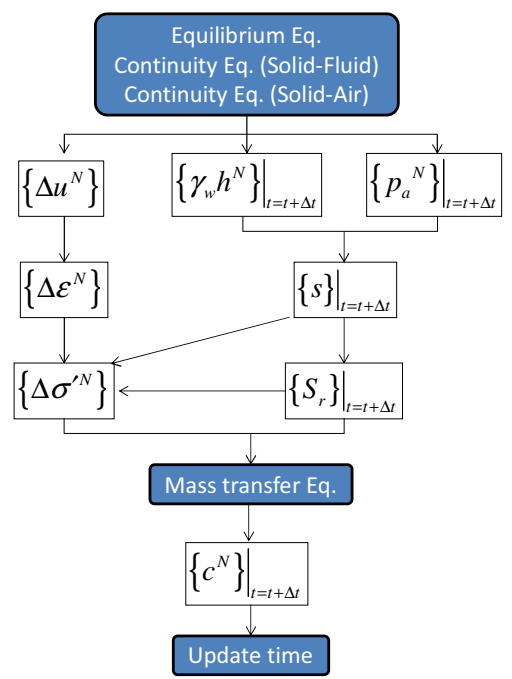

Fig. 4. Numerical calculation flow diagram

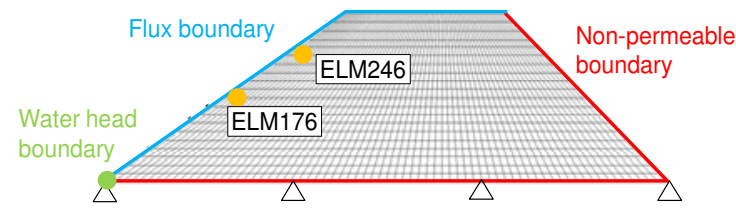

Fig. 5. Analytical mesh and boundary conditions

Table. 1. Input material parameters

\begin{tabular}{|c|c|c|c|c|}
\hline$\lambda$ & $\kappa$ & $M$ & $m$ & $n_{E}$ \\
\hline 0.97 & 0.009 & 1.375 & 0.8 & 1.0 \\
\hline$a$ & $n_{s}$ & $\gamma$ & $D_{x}$ & $D_{y}$ \\
\hline 10.0 & 1.0 & 0.17 & $2.4 \times 10^{-3}$ & $2.4 \times 10^{-3}$ \\
\hline
\end{tabular}

$D_{r}, D_{v}$ : Dispersion coefficient, unit $\mathrm{m}^{2} /$ day between suction and degree of saturation, was modelled by Kawai et al. (2007) [4] considering hysteresis.

\subsection{Soil/water/air/soluble material coupled problem}

The equilibrium equation, the continuity equations, and mass transfer equation were spatially discretized with the application of the finite element method and temporally discretized with the application of Euler's method. Here, the mass transfer equation expressed by Eq.(4) is a secondary expression consisting of concentration and other unknowns, displacement, water head and air water head. Unknowns were first calculated from the equilibrium equation of total stress and equations (11), (12), and (13). Obtained unknowns were substituted into Eq.(7) to calculate concentration. The flow of numerical calculations is shown in Fig.4.

\section{Simulation procedures and conditions}

The analysis mesh and boundary conditions are as shown in Fig.5 for the model test shown in Fig.1. The bottom and right sides of the analytical area were not permeable. The rainfall infiltration surfaces on the crown and left side embankment slope were expressed as a flux boundary corresponding to rainfall intensity. The slope

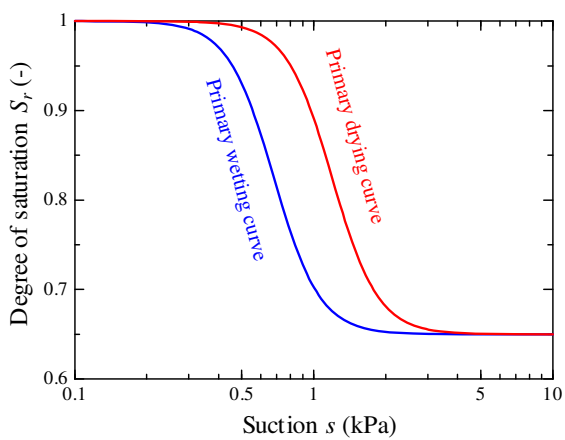

Fig. 6. Soil water retention characteristic curves

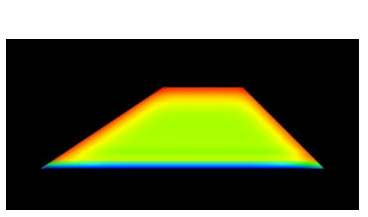

(a) Low permeability

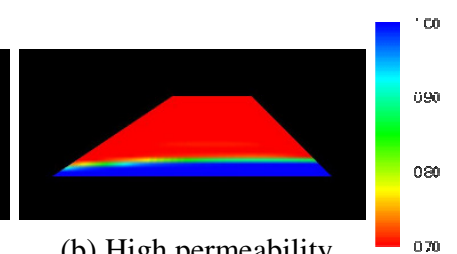

(b) High permeability
Fig. 7. Initial distribution of degree of saturation

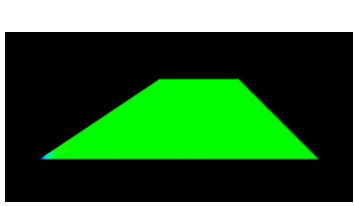

(a) Low permeability

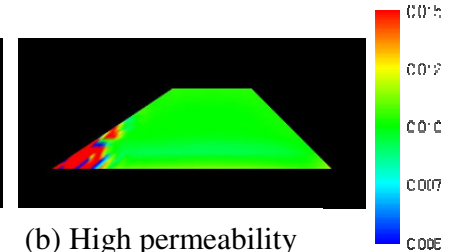

(b) High permeability
Fig. 8. Initial distribution of relative solute concentration 


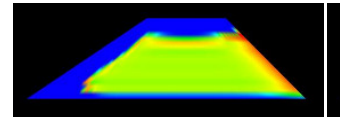

(a) $2.5 \mathrm{~h}$ rainfall

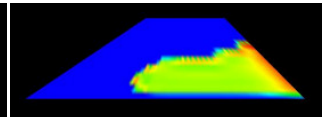

(b) $5 \mathrm{~h}$ rainfall

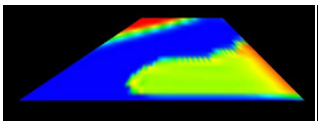

(c) $6 \mathrm{~h}$ after rainfall

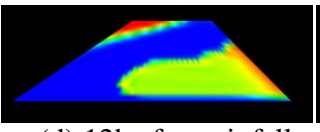

(d) $12 \mathrm{~h}$ after rainfall

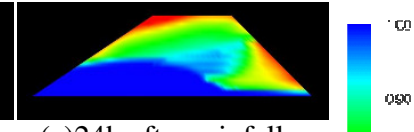

(e) $24 \mathrm{~h}$ after rainfall

Fig. 9. Degree of saturation distribution $(10 \mathrm{~mm} / \mathrm{h})$ within low permeability embankment

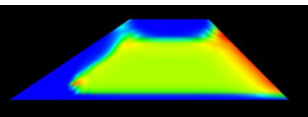

(a) $5 \mathrm{~h}$ rainfall

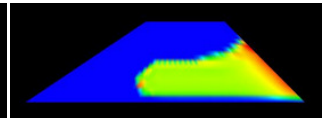

(b) $10 \mathrm{~h}$ rainfall

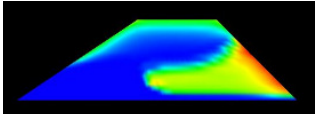

(c) $6 \mathrm{~h}$ after rainfall

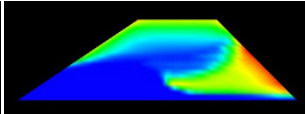

(d) $12 \mathrm{~h}$ after rainfall

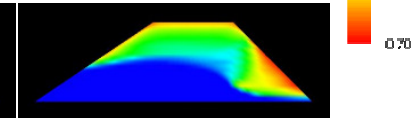

(e)24h after rainfall

Fig. 10. Degree of saturation distribution $(5 \mathrm{~mm} / \mathrm{h})$ within low permeability embankment

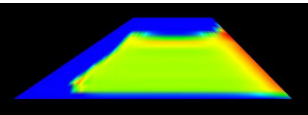

(a) $12.5 \mathrm{~h}$ rainfall

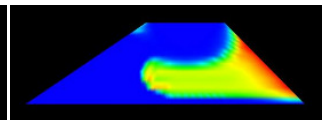

(b) $25 \mathrm{~h}$ rainfall

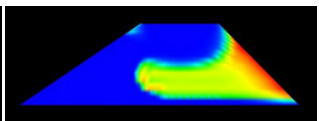

(c) 6h after rainfall

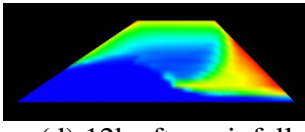

(d) $12 \mathrm{~h}$ after rainfall

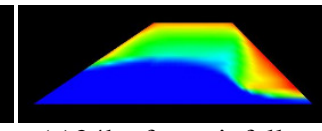

(e)24h after rainfall

Fig. 11. Degree of saturation distribution $(2 \mathrm{~mm} / \mathrm{h})$ within low peameability embankment

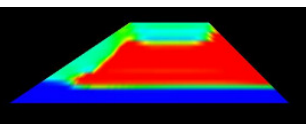

(a) $12.5 \mathrm{~h}$ rainfall

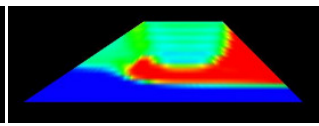

(b) $25 \mathrm{~h}$ rainfall

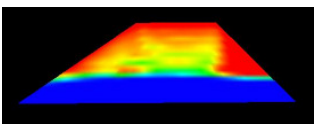

(c) $6 \mathrm{~h}$ after rainfall

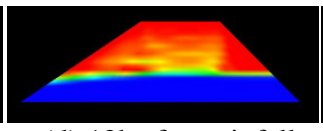

(d) $12 \mathrm{~h}$ after rainfall

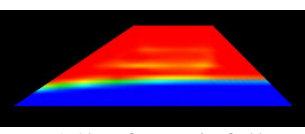

(e)24h after rainfall

Fig. 12. Degree of saturation distribution $(10 \mathrm{~mm} / \mathrm{h})$ within high peameability embankment

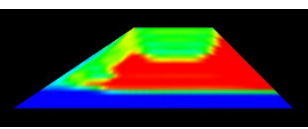

(a) $5 \mathrm{~h}$ rainfall

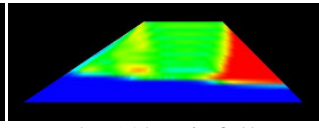

(b) $10 \mathrm{~h}$ rainfall

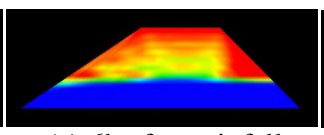

(c) $6 \mathrm{~h}$ after rainfall

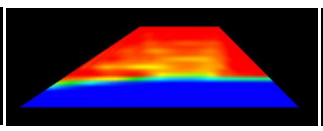

(d) $12 \mathrm{~h}$ after rainfall

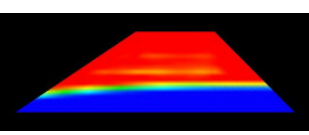

(e)24h after rainfall

Fig. 13. Degree of saturation distribution $(5 \mathrm{~mm} / \mathrm{h})$ within high permeability embankment

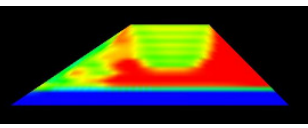

(a) $12.5 \mathrm{~h}$ rainfall

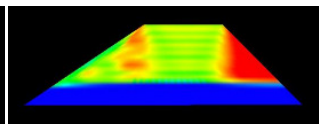

(b) $25 \mathrm{~h}$ rainfall

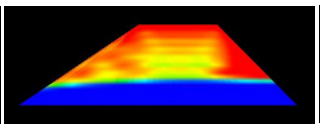

(c) $6 \mathrm{~h}$ after rainfall

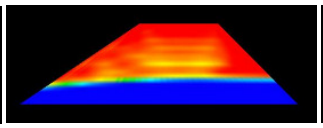

(d) $12 \mathrm{~h}$ after rainfall

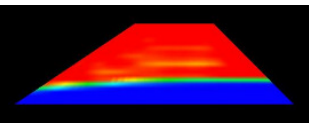

(e)24h after rainfall

Fig. 14. Degree of saturation distribution $(2 \mathrm{~mm} / \mathrm{h})$ within high peameability embankment

toe was assumed as a drainable boundary and a pressure head of $-0.1 \mathrm{~m}$ was applied. Moreover, the assumption that soluble material can be advected by seepage flow, is dispersed in pore-water and cannot be drained from the analytical area was made. Table 1 summarizes material properties used for the simulations. The soil water retention characteristics obtained from lab-tests were modelled as shown in Fig.6 and used for simulations. The permeability measured by lab permeability tests in accordance with the degree of compaction was $4.0 \times 10^{-6}: 2.0 \times 10^{-4}(\mathrm{~m} / \mathrm{sec})$. In total, three variations of permeability, $\quad\left(k_{x}, k_{y}\right)=\left(1.0 \times 10^{-6}, 0.5 \times 10^{-6}\right)$, $\left(1.0 \times 10^{-5}, 0.5 \times 10^{-5}\right), \quad\left(2.0 \times 10^{-5}, 1.0 \times 10^{-5}\right)$, were provided and anisotropic permeability was considered. The rainfall infiltration simulation was conducted via the following process. At first, the initial condition, a degree of saturation of 0.8 , a suction of $1 \mathrm{kPa}$, and a relative solute concentration of 0.010 , was set for all elements to express the condition just after embankment construction. A rest period of 2 days was then applied. Figures 7 and 8 show the distribution of the degree of saturation and the relative solute concentration, respectively, after the resting period. The high permeability embankment exhibits earlier redistribution of pore water due to the elevation head difference, and a phreatic surface appears. The soluble material concurrently advects and dissipates within the embankment according to permeability. Next, rainfall was applied to the crown and left side slope. Here, three kinds of rainfall intensity, 10,5 and $2 \mathrm{~mm} / \mathrm{h}$, were considered and rainfall duration time was set to 5,10 and 25 hours, respectively.

\section{Simulation results and discussions}

Figures 9,10 and 11 show changes in the distribution of the degree of saturation within the low permeability embankment under rainfall. These figures are arranged according to rainfall intensity and show total precipitation amounts of $25 \mathrm{~mm}$ and $50 \mathrm{~mm}$. Soil moisture distribution is shown to depend on rainfall intensity, even for the same total precipitation amount. This is because smaller rainfall intensity occurs over a longer rainfall duration, and infiltrated rainwater can penetrate more deeply. Moreover, unsaturated permeability influences infiltration behaviour. Unsaturated permeability depends on the degree of saturation, as expressed by Eq. 11 . When rainfall penetrates the ground surface, the area close to the ground surface shows a higher degree of saturation. On the slope surface, the higher soil moisture area expands parallel to the slope surface. At the same time, a relatively higher permeability area also expands parallel to the slope surface. Though infiltrated rainwater essentially descends vertically due to the elevation head difference, rainwater which penetrates through the slope surface is attracted toward the higher permeability area parallel to 


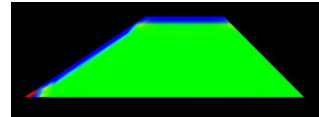

(a) $2.5 \mathrm{~h}$ rainfall

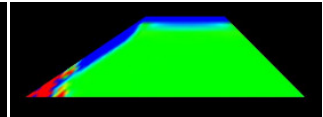

(b) $5 \mathrm{~h}$ rainfall

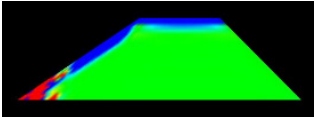

(c) $6 \mathrm{~h}$ after rainfall

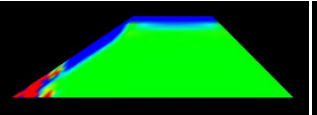

(d) $12 \mathrm{~h}$ after rainfall

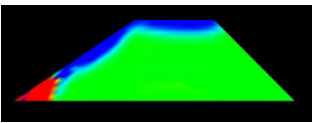

(e)24h after rainfall

Fig. 15. Relative concentration distribution $(10 \mathrm{~mm} / \mathrm{h})$ within low permeability embankment

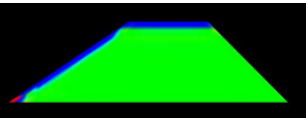

(a) $5 \mathrm{~h}$ rainfall

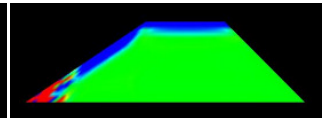

(b) $10 \mathrm{~h}$ rainfall

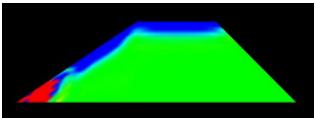

(c) $6 \mathrm{~h}$ after rainfall

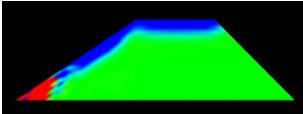

(d) $12 \mathrm{~h}$ after rainfall

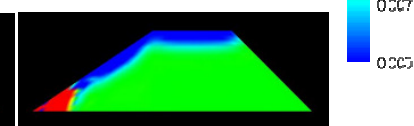

(e) $24 \mathrm{~h}$ after rainfall

Fig. 16. Relative concentration distribution $(5 \mathrm{~mm} / \mathrm{h})$ within low permeability embankment

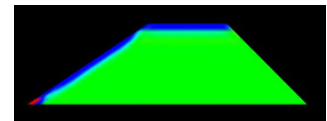

(a) $12.5 \mathrm{~h}$ rainfall

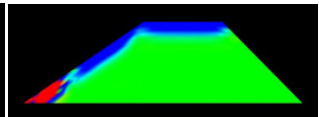

(b) $25 \mathrm{~h}$ rainfall

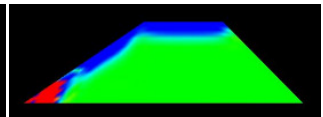

(c) $6 \mathrm{~h}$ after rainfall

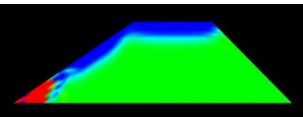

(d) $12 \mathrm{~h}$ after rainfall

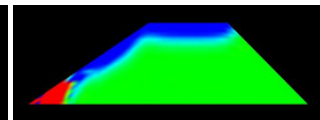

(e)24h after rainfall

Fig. 17. Relative concentration distribution $(2 \mathrm{~mm} / \mathrm{h})$ within low permeability embankment

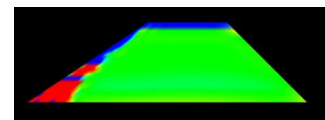

(a) $12.5 \mathrm{~h}$ rainfall

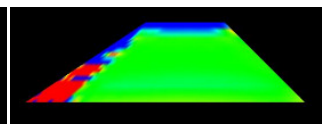

(b) $25 \mathrm{~h}$ rainfall

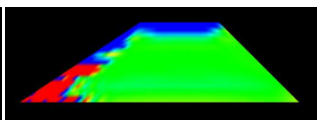

(c) $6 \mathrm{~h}$ after rainfall

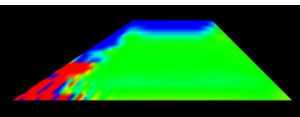

(d) $12 \mathrm{~h}$ after rainfall

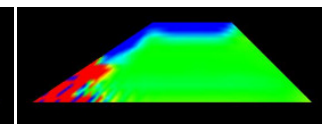

(e) $24 \mathrm{~h}$ after rainfall

Fig. 18. Relative concentration distribution $(10 \mathrm{~mm} / \mathrm{h})$ within high permeability embankment

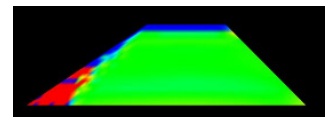

(a) $5 \mathrm{~h}$ rainfall

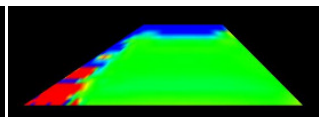

(b) $10 \mathrm{~h}$ rainfall

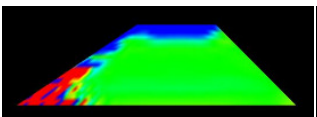

(c) $6 \mathrm{~h}$ after rainfall

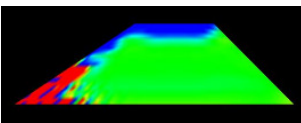

(d) $12 \mathrm{~h}$ after rainfall

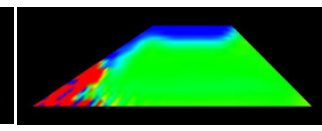

(e) $24 \mathrm{~h}$ after rainfall

Fig. 19. Relative concentration distribution $(5 \mathrm{~mm} / \mathrm{h})$ within high permeability embankment

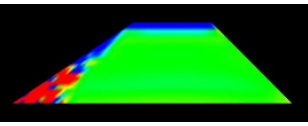

(a) $12.5 \mathrm{~h}$ rainfall

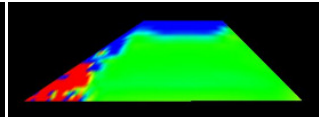

(b) $25 \mathrm{~h}$ rainfall

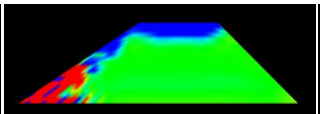

(c) $6 \mathrm{~h}$ after rainfal

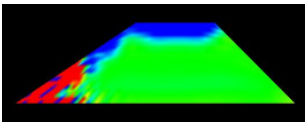

(d) $12 \mathrm{~h}$ after rainfall

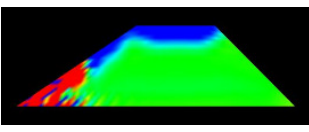

(e) $24 \mathrm{~h}$ after rainfall

Fig. 20. Relative concentration distribution $(2 \mathrm{~mm} / \mathrm{h})$ within high permeability embankment

the slope surface. This tendency is more evident under stronger rainfall intensity. On the other hand, under weaker rainfall intensity, rainwater which penetrates through the crown can descend vertically more deeply and can more easily reach the bottom of the embankment. Consequently, after rainfall, infiltrated rainwater can be categorized by the flux around the slope surface and the downward flux. The rainwater that penetrates the slope surface directly drains at the slope toe, while rainwater that penetrates through the crown first becomes a phreatic surface before draining. In this case, it is difficult to drain infiltrated rainwater that forms a phreatic surface. Smaller rainfall intensity exhibits a more evident phreatic surface. Figures 12, 13 and 14 show changes in the degree of saturation within high permeability embankment. Downward flux is more evident in the higher permeability embankment and a higher phreatic surface is generated. Moreover, even after rainfall, the phreatic surface remains high.

Figures 15, 16 and 17 show changes in the distribution of relative solute concentration within the low permeability embankment. Both rainwater infiltrating around the slope surface and rainwater forming the phreatic surface are finally drained at the slope toe, and the relative solute concentration around the slope toe is high. Overall, areas around the crown and slope surface show low concentrations. Since soluble material is advected by pore water, it is washed away where pore water flows. Consequently, the distribution of relative solute concentration is dependent on rainfall intensity. Though it is difficult to discriminate clear differences in distribution from figures, relative solute concentration around the slope surface is low in the high permeability embankment, while relative solute concentration around the crown is low in the low permeability embankment. These tendencies are subject to the behaviour of infiltrated rainwater detailed before. Consequently, the high $\mathrm{pH}$ water leaches from the embankment, as shown in Fig. 2. Figures 18, 19 and 20 show changes in the distribution of relative solute concentration within the high permeability embankment. Since the phreatic surface is clearly generated within the high permeability embankment, there is little decrease in the relative solute concentration around the bottom of the embankment.

Here, we focus two elements at the slope surface, as shown in Fig. 5. Figure 21 shows changes in the degree of saturation at the middle of the slope surface (element 176) and the relative upper side of the slope surface (element 246). In this figure, the times when rain stops are indicated by dashed lines. These elements in the low permeability embankment reach saturated conditions under any rainfall intensity and remain saturated for some time, even after rainfall stops. This is because water is supplied from the upper side of the slope surface. Therefore, the decrease in degree of saturation at the middle element is smaller than at the upper element. Moreover, pore water drains more difficultly under lower rainfall intensity. On the other hand, in the high permeability embankment, elements on the slope surface 


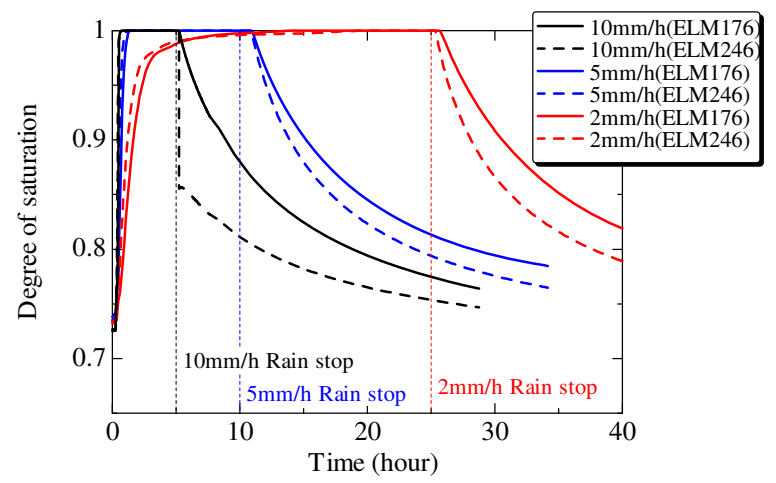

(a) Low permeability embankment

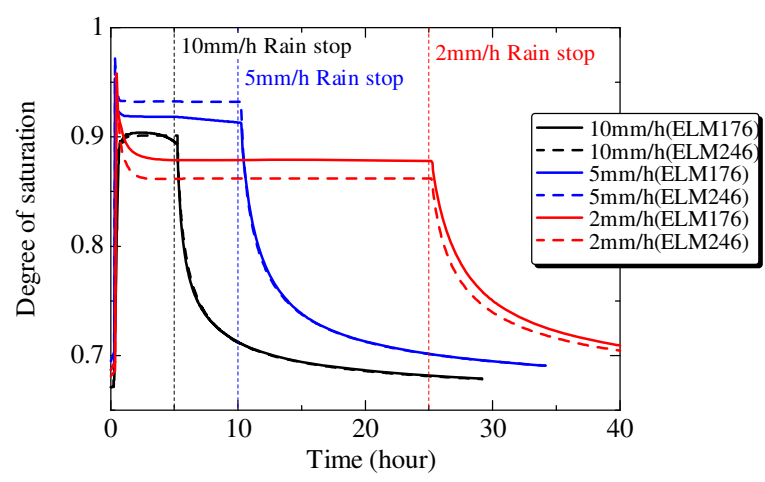

(b) High permeability embankment

Fig. 21. Changes in degree of saturation at the element on the slope surface

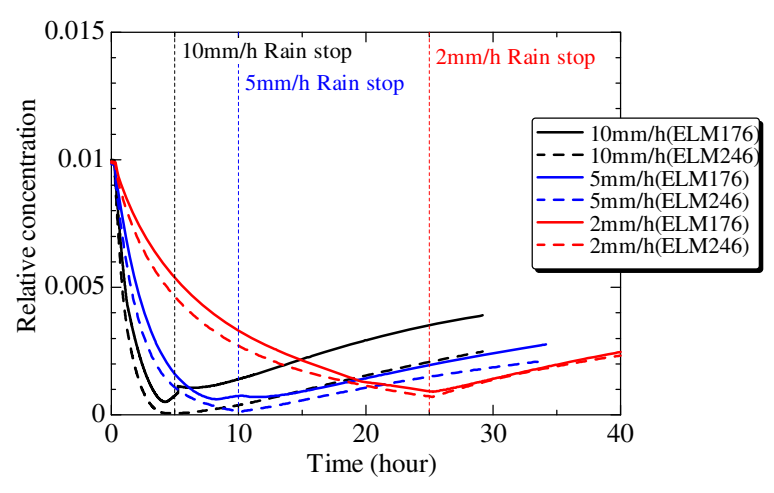

(a) Low permeability embankment

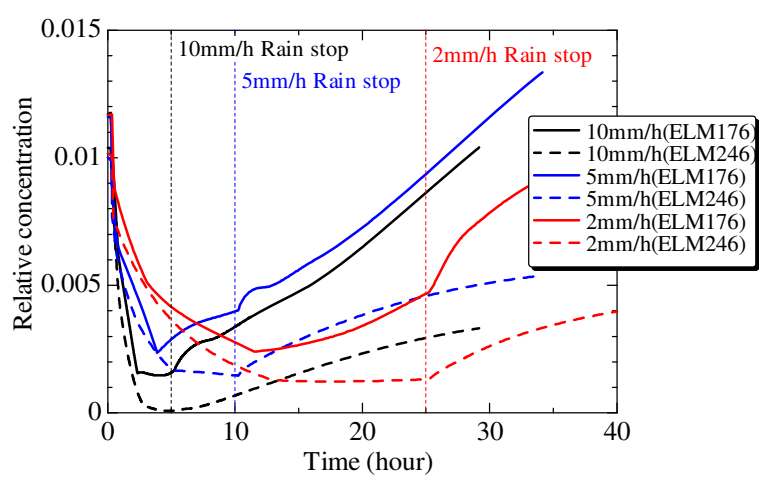

(b) High permeability embankment

Fig. 22. Changes in relative concentration at the element on the slope surface

do not reach saturation, and pore water drains easily. Figure 22 shows changes in the relative solute concentration at the two elements on the slope surface. In the low permeability embankment, relative solute concentration keeps decreasing under rainfall, and it gradually recovers after rainfall. This is because soluble material is washed away under rainfall, and it is supplied from the slope toe and inner element due to dissipation. Since the accumulation of soluble material at the slope toe is more evident in the high permeability embankment, relative solute concentration on the slope surface recovers earlier. However, the soluble material does not actually accumulate, instead it leaches with drainage from the embankment. In this paper, to simplify boundary conditions related to soluble material, nonpermeable conditions for soluble material were applied to every boundary, which caused accumulation. The best way to apply boundary conditions for soluble materials remains an open question.

\section{Conclusions}

In this study, with a view to use steel slag as a solidification material for constructing embankment with low-quality soil, the effect of rainfall infiltration on a model embankment constructed with a soil and steel slag mixture was simulated. The following results were obtained.

(1) The behaviour of infiltrated rainwater depends on rainfall intensity. Flux parallel to the slope surface and downward flux are apparent, with their distribution depending on rainfall intensity.

(2) Soluble material is advected by flux induced by rainfall infiltration. The simulation results in this study suggest that more soluble material leaches from the higher permeability embankment under stronger rainfall intensity.

\section{References}

1. Y. Mualem, Water Resour. Res., 12, 3, 513-522 (1976)

2. R. J. Lenhard, J. C. Parker, Water Resour. Res., 23, 12, 2197-2206 (1987)

3. S. Ohno, K. Kawai, S. Tachibana, Doboku Gakkai Ronbunshuu C, 63, 4, 1132-1141 (2007) (in Japanese)

4. K. Kawai, A. Iizuka, E. Hayakawa, W. Wang, Soils and Foundations, 47, 2, 195-205 (2007) 